\title{
Um professor de química, um conteúdo e dois contextos ensaiO escolares: do PCK pessoal para o PCK em ação
}

\author{
Aroldo Nascimento Silva ${ }^{1}$ \\ https://orcid.org/0000-0003-3493-6336 \\ Carmen Fernandez ${ }^{1}$ \\ https://orcid.org/0000-0003-2201-6241 \\ ${ }^{1}$ Universidade de São Paulo, Instituto de Química, São Paulo, SP - Brasil
}

\begin{abstract}
Resumo:
Neste trabalho, analisamos como um professor, inserido em dois contextos escolares distintos, mobiliza seus conhecimentos para o ensino de química. Adotamos como referencial teórico a base de conhecimentos de professores, mais especificamente $\mathrm{o}$ Conhecimento Pedagógico do Conteúdo (PCK). Os dados compreendem registros audiovisuais das aulas, entrevistas, respostas ao instrumento Representação de Conteúdo (CoRe), reflexões vídeo-estimuladas e observação participante. As
\end{abstract}

Palavras-chave:

Conhecimento

Pedagógico do Conteúdo; Contexto de aprendizagem; Conhecimentos docentes.

Un docente de química, un contenido y dos contextos escolares: del PCK personal al PCK en acción

\section{Resumen:}

En este trabajo, analizamos cómo un docente, insertado en dos contextos escolares distintos, moviliza sus conocimientos para la enseñanza de la química. Adoptamos como marco teórico el conocimiento base de los docentes, más específicamente el Conocimiento Didáctico del Contenido (PCK). Los datos comprenden registros audiovisuales de las clases, entrevistas, respuestas al instrumento Representación del Contenido (CoRe), reflexiones videoestimuladas y observación participante. Los

Palabras clave:

Conocimiento

Didáctico del

Contenido; Contexto

de aprendizaje;

Conocimientos de

los docentes. análisis se basaron en interacciones discursivas y en el Modelo Consensual Refinado. A partir de estos datos accedemos y 
analizamos el conocimiento pedagógico del contenido personal y en acción del docente y señalamos los aportes recibidos por los diferentes actores y contextos que hicieron que el docente actuara diferentemente en las dos escuelas.

\title{
A chemistry teacher, one content and two school contexts: from the personal PCK to the enacted PCK
}

\begin{abstract}
:
In this work, we analyze how a teacher, inserted in two different school contexts, mobilizes his knowledge for teaching chemistry. We adopted as the theoretical background framing the teachers' professional knowledge, more specifically the Pedagogical Content Knowledge (PCK). The data comprise audiovisual records of classes, interviews, answers to the Content Representation instrument (CoRe), stimulated video reflections and participant observation. The analyzes were based on the discursive interactions and the Refined Consensus Model. From these data, we access and analyze the personal and the enacted pedagogical content knowledge of the teacher and point out the contributions received by the different actors and contexts that made the teacher act differently in the two schools.
\end{abstract}

Keywords:

Pedagogical Content

Knowledge;

Learning context;

Teaching knowledge.

\section{INTRODUÇÃO}

A profissão de professor pressupõe a aquisição de conhecimentos específicos, que faz com que esse profissional tenha a especialidade de ensinar algum tópico a alguém. Dentre esses conhecimentos, o Conhecimento Pedagógico do Conteúdo (Pedagogical Content Knowledge - PCK ) constitui-se como parte central. Um importante argumento para estudá-lo é que professores que possuem altos níveis de PCK são mais competentes em dar apoio às aprendizagens dos estudantes (Baumert et al., 2010; Rollnick, Bennet, Rhemtula, Dharsey, \& Ndlovu, 2008). O uso da sigla em inglês visa facilitar o estabelecimento de relações com a literatura internacional, uma vez que a sigla já se tornou bastante difundida e conhecida, extrapolando até mesmo a denominação do constructo.

Desde a década de 1980, Shulman tem argumentado a favor da profissionalização docente, dando visibilidade a uma base de conhecimentos necessária para alguém se tornar professor, a qual envolveria os conhecimentos: do Conteúdo, Pedagógico, do Currículo, Conhecimento Pedagógico do Conteúdo, dos Estudantes, dos Contextos, Conhecimento dos Objetivos, Finalidades e Valores Educacionais, e de seus Fundamentos Filosóficos e Históricos (Shulman, 1987). Dentre esses conhecimentos, ressalta-se o PCK, um tipo de mescla entre o conhecimento pedagógico e específico sobre um determinado tópico que o professor precisa possuir para ser o melhor professor possível. A partir de então, observa-se na literatura um aumento significativo de 
trabalhos nas áreas de Ciências da Natureza e Matemática que discutem, interpretam e expandem suas ideias (Abell, 2007, 2008; Fernandez, 2015; Friedrichsen, Driel, \& Abell, 2011; Gess-Newsome, 2015; Grossman, 1990; Hume, Cooper, \& Borowski, 2019; Kind, 2009; Magnusson, Krajcik, \& Borko, 1999; Marcelo, 2005; Park, \& Oliver, 2008; Park, Jang, Chen, \& Jung, 2011; Rollnick et al., 2008; Van Driel, \& Berry, 2012).

Além das categorias que fundamentam o conhecimento base dos professores, Shulman (1987) apresentou nesse artigo o Modelo de Raciocínio Pedagógico e Ação (MRPA), de modo a deixar explícitas as etapas envolvidas no desenvolvimento profissional de um professor, ou seja, como o professor desenvolve o seu PCK. Esse primeiro modelo já apresentava a ideia de raciocínio pedagógico do professor sobre um dado conteúdo para o ensino, revelando-se um modelo dinâmico e cíclico de reflexão e ação docente. Tal processo seria constituído de compreensão, transformação, instrução, avaliação, reflexão e nova compreensão (nos termos usados por Shulman, 1987). Esse processo dinâmico ocorre no dia a dia do professor, e vai sendo enriquecido pelo contexto em que se sucede, como resultado das interações sociais que a atividade educativa implica e os momentos distintos que caracterizam a prática docente. Assim, o ciclo de planejar, ensinar e refletir vai se repetindo na prática educativa de um professor e vai incrementado seu repertório através de seu raciocínio pedagógico.

Nesse mesmo artigo, Shulman (1987) compara professores iniciantes e experientes e coloca que o que irá distinguí-los é o repertório de formas pedagógicas ao lidar com um conteúdo específico, a sua capacidade de transformar um determinado conhecimento que possui em formas pedagogicamente poderosas para serem apresentadas aos estudantes.

Neste sentido, diversos pesquisadores apontam o PCK como um tipo de conhecimento desenvolvido com a experiência (Abell, 2007; Grossman, 1990; Kind, 2009; Van Driel, De Jong, \& Verloop, 2002). Portanto, professores iniciantes geralmente apresentam um PCK mais limitado em relação aos professores experientes. Por outro lado, somente a experiência não garante um bom PCK, pois o desenvolvimento deste tipo de conhecimento ocorre pela combinação da experiência com reflexão e a partir de trocas com outros profissionais.

Na literatura, observam-se diversas conceituações para o PCK, com diferentes interpretações e modelos (Fernandez, 2011). Apesar dessa diversidade, constata-se que a maioria dos trabalhos não adota um modelo único para fundamentação e interpretação dos dados de pesquisa, sendo que, na área de Ciências da Natureza, os mais usados são os modelos de Magnusson et al. (1999) e de Grossman (1990) (Carlson, \& Daehler, 2019; Fernandez, \& Goes, 2014; Helmes, \& Stokes, 2013).

A partir de discussões sobre os atributos do PCK, as ferramentas adequadas para o seu acesso, análise e uma explicação para os resultados nem sempre consensuais de investigações sobre o PCK, foi proposto, em 2012, uma reunião de pesquisadores e, dela, resultou o que ficou conhecido como Modelo Consensual (MC). Nesse modelo, a base de conhecimentos de professores está constituída por conhecimento do conteúdo, pedagógico, curricular, dos estudantes e da avaliação. Entretanto, como pontuam Carlson e Daehler (2019), apesar do nome, o MC não atingiu o consenso esperado e não vem sendo muito utilizado. Além disso, nas pesquisas em que foi utilizado, houve a percepção de que o MC estava sendo interpretado e operacionalizado de forma distinta, 
o que continuou gerando uma série de dados qualitativos e quantitativos divergentes (Gess-Newsome, 2015).

Assim, novos encontros foram propostos, onde investigações foram revisitadas no que concerne aos objetivos, dados coletados, instrumentos de coleta desses dados e procedimentos de acesso ao PCK no ensino de ciências, obtendo-se um entendimento mais aprimorado sobre o PCK na educação científica, que resultou na proposição do Modelo Consensual Refinado (MCR) (Carlson, \& Daehler, 2019). O MCR tem a pretensão de deixar mais explícito o que a comunidade científica entende por PCK, como ele se desenvolve e quais são as contribuições ao seu desenvolvimento. Pretende, assim, fazer uma síntese de ideias colocadas em modelos anteriores.

O MCR propõe-se ainda a revelar o caráter dinâmico do PCK, seu uso, seu desenvolvimento e os atores que contribuem para seu incremento. Apresenta, também, os mesmos conhecimentos da base do modelo consensual, acrescidos do contexto e do processo de raciocínio pedagógico do professor, além das interações com outros atores que influenciam no desenvolvimento profissional do professor. Apresenta distintos domínios de PCK, de modo a estabelecer, diferenciar e apresentar as relações entre conhecimentos teóricos e práticos. Assim, pretende estabelecer conexões entre as camadas de conhecimento e práticas que moldam e informam a prática educativa dos professores ao longo de seu desenvolvimento profissional e, por sua vez, conecta aos resultados dos alunos. O MCR estabelece três distintos domínios de PCK, o PCK coletivo, o PCK pessoal e o PCK em ação. O PCK coletivo pode ser entendido como um coletivo local (entre um grupo de professores numa escola) ou um coletivo canônico (conhecimentos consensuais acumulados e revisados por pares e que formam o corpo de conhecimentos de ensino de um assunto em particular).

Na presente investigação, lançamos mão do MCR para analisar a prática de um professor de química experiente atuando em duas escolas, no intuito de compreender quais aspectos são modificados nos distintos contextos, de modo a acessar seu PCK em ação e estabelecer as possíveis conexões com os demais domínios e atores ao lecionar um mesmo conteúdo, utilizando o mesmo material curricular que foi elaborado por ele, em duas instituições escolares com projetos distintos.

Dessa forma, nossas questões de pesquisa são: a que aspectos da sala de aula o professor atribui as mudanças observadas? Como os estudantes influenciam a forma de ensinar do professor?

As respostas para estas questões passam pelo entendimento do repertório de conhecimentos que compõe o PCK pessoal desse professor e como ele o mobiliza em seu PCK em ação em função do contexto escolar para tornar o conteúdo específico pedagogicamente acessível aos estudantes, levando em conta o contexto da aprendizagem.

\section{O Modelo Consensual Refinado (MCR) do PCK}

O MCR do PCK conecta visualmente diferentes camadas complexas de conhecimentos e experiências, bem como as influências que moldam a prática educativa 
dos professores durante sua trajetória profissional, sendo constituído por múltiplas camadas, das quais o professor ocupa a camada mais interna (Figura 1). Isso revela, por um lado, a importância atribuída aos diferentes aspectos que são mobilizados ao se ensinar ciências em uma sala de aula específica e, por outro, reforça o valor das pesquisas que se centram no raciocínio pedagógico do professor e na natureza dinâmica do PCK (Carlson, \& Daehler, 2019).

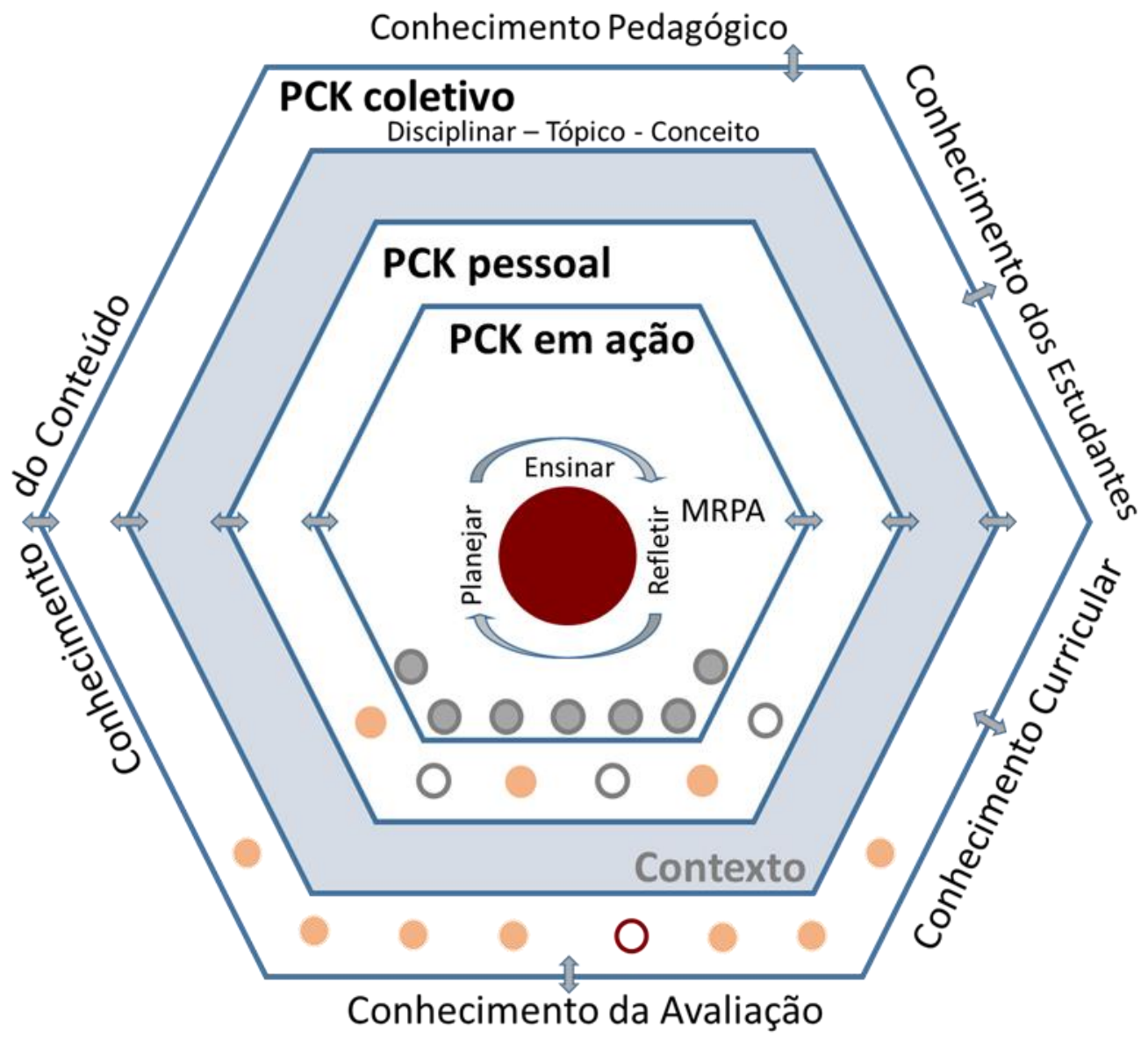

Figura 1: Modelo Consensual Refinado (MCR) do PCK adaptado do modelo proposto por Carlson e Daehler (2019). No modelo, são representados os distintos domínios do PCK. Na camada externa aparece a base de conhecimentos profissionais dos professores (Conhecimento do Conteúdo, Pedagógico, dos Estudantes, Curricular e de Avaliação) que informa o PCK coletivo. Este, por sua vez, informa e influencia o PCK pessoal, que é específico para um professor. O PCK em ação é o resultado de um professor aplicando e adaptando seu PCK pessoal a um determinado contexto de aprendizagem. As setas representam a natureza dinâmica do conhecimento e seu movimento nos diferentes domínios do PCK (coletivo, pessoal e em ação). O professor no centro (vinho) enfatiza a natureza idiossincrática do PCK. Os atores que influenciam o professor estão em cores distintas representando pesquisadores, acadêmicos e outras contribuições (laranja), outros professores (vinho vazado), alunos (cinza vazado) e os resultados dos alunos (cinza cheio). O Modelo de Raciocínio Pedagógico e Ação (MRPA) representa o raciocínio pedagógico do professor em suas práticas diárias de planejar, ensinar, refletir e replanejar. A cada ciclo, novas compreensões são incorporadas ao seu repertório incrementando seu PCK. 
Uma característica importante desse modelo é a identificação de três domínios do PCK - o PCK coletivo, o PCK pessoal e o PCK em ação - que descrevem, respectivamente, o conhecimento profissional especializado compartilhado por uma comunidade de educadores; o conhecimento profissional personalizado, idiossincrático de um professor; e o subconjunto único de conhecimentos que um professor utiliza no seu dia a dia ao engajar-se no seu raciocínio pedagógico e que se traduz em suas ações de sala de aula e que envolvem as ações de planejar, ensinar e refletir sobre a prática, atingindo uma nova compreensão. Ou seja, o modelo representa essa dinâmica complexa que se dá desde o conhecimento coletivo canônico compreendido por muitos, e que o professor tem acesso de alguma forma durante sua formação inicial e continuada, até o único subconjunto de conhecimentos que um professor individual possui, adapta e mobiliza em sala de aula. E apresenta, ainda, as distintas contribuições a esses domínios. Entre a camada de PCK coletivo e PCK pessoal está representada a camada relativa ao contexto de aprendizagem que irá atuar como um filtro entre o modelo teórico e os condicionantes do contexto educativo e que será traduzido na prática educativa. O contexto inclui vários elementos relevantes. Por exemplo, em nível federal, as políticas públicas nacionais; em nível estadual, os currículos dos estados; e na escola propriamente dita, seu projeto político pedagógico, valores da comunidade e as características dos estudantes.

No modelo, são representadas ainda as trocas de conhecimentos entre as várias camadas por setas bidirecionais. Assim, os conhecimentos e habilidades que o professor possui de cada domínio acabam sendo filtrados e/ou amplificados e se traduzem em seu PCK pessoal, e este é mobilizado em sala de aula na forma de PCK em ação. Tais filtros incluem as crenças e atitudes dos professores, a visão da ciência, o papel de professores e alunos etc.

Na camada mais interna, do PCK em ação, aparece a figura do professor e está representado seu raciocínio pedagógico nas ações de planejar, ensinar e refletir, algo que remete diretamente ao Modelo de Raciocínio Pedagógico e Ação (MRPA) de Shulman (1987).

As setas bidirecionais representam o caráter dinâmico dessas trocas. Assim, o PCK em ação se abastece do PCK pessoal e do PCK coletivo. Por outro lado, as experiências vividas e refletidas na prática se traduzem em PCK em ação e podem retroalimentar e dar subsídios para o incremento do PCK pessoal do professor e, a partir de conversas e compartilhamento de experiências com outros professores, um indivíduo pode contribuir para o PCK coletivo local de seu grupo de professores e ainda contribuir para o PCK coletivo canônico de sua área (Carlson, \& Daehler, 2019). Assim, o modelo tenta traduzir, além dos conhecimentos necessários ao professor, como ocorre a dinâmica de desenvolvimento de tais conhecimentos e as influências de todo esse processo. Explicita ainda o trajeto dessas relações entre o conhecimento coletivo, pessoal e o que é colocado em ação, e como diferentes sujeitos participam e influenciam no desenvolvimento desses conhecimentos.

Ao ensinar ciências - seja planejando, ensinando e refletindo sobre os resultados obtidos pelos alunos -, o professor mobiliza o seu PCK em ação. Este conhecimento é particular para cada professor e sofre forte influência do contexto, dos resultados dos estudantes, das contribuições de outros professores e de estudantes, além de outras 
contribuições. Ele encontra-se representado no círculo interno do modelo, com professor e alunos interagindo durante o processo de mediação pedagógica e o professor reagindo aos resultados de seus alunos. Representa os conhecimentos e habilidades específicas utilizados por um professor ao ensinar um determinado conteúdo, considerando uma configuração particular de ensino.

O PCK pessoal, por sua vez, é o conhecimento que um professor possui, que resulta das experiências e repertórios acumulados no decorrer de sua trajetória profissional. Esse conjunto de conhecimentos e habilidades que constitui o PCK pessoal é algo em constante desenvolvimento, sendo alimentado pela sua formação inicial, pelas interações com colegas de profissão, pesquisadores da área de ensino, pela leitura de artigos, livros e também em função de sua participação em eventos de desenvolvimento profissional, bem como contribuições de todos os alunos. Assim, o PCK pessoal é uma espécie de repertório de conhecimentos e habilidades que é alimentado tanto pelo PCK coletivo como pelo PCK em ação, e que o professor lança mão durante sua prática de ensino. Como se observa no modelo, essa camada de conhecimento informa e é informada pelo subconjunto menor, no caso, o PCK em ação. Ao ensinar um determinado conteúdo para um grupo de alunos em particular, o professor obviamente não mobiliza todo o seu repertório em sua ação, em vez disso, utiliza aquilo que atende àquele contexto, com base em suas experiências anteriores, e na resposta fornecida pelos alunos e, ainda, com base no próprio contexto educativo no qual este professor está inserido (Carlson, \& Daehler, 2019).

Com relação ao PCK coletivo, diferentemente dos demais, trata-se de um domínio de conhecimento compartilhado, que resulta das contribuições de um coletivo de pesquisadores ou de educadores que atuam em uma determinada área do conhecimento e que também pode incluir as contribuições do professor. O PCK coletivo pode representar tanto o PCK que está na literatura produzido por pesquisadores da área (PCK canônico) como pode representar o PCK de um grupo de professores numa escola ou numa comunidade de aprendizagem profissional (PCK coletivo local). Como exemplo, as respostas ao instrumento CoRe (Representação de Conteúdo) de um grupo de professores pode ser caracterizada como o PCK coletivo local. Entretanto, se o CoRe for respondido por um único professor, ele será característico do PCK pessoal desse professor.

No MCR, o conhecimento especializado de um professor pode ainda vir em diferentes níveis: disciplinar (por ex. argumentação em ensino de ciências), tópico (por ex. fotossíntese), ou conteúdo (por ex. estrutura da matéria). Esses diferentes níveis podem estar presentes no PCK coletivo, pessoal e em ação. O contexto de aprendizagem é um fator que influencia as ações do professor e os resultados dos alunos. O contexto funciona, assim, como amplificador e também como filtro do conhecimento e habilidades do professor, e acaba mediando suas ações.

É importante destacar que, no modelo, o contexto de aprendizagem não se restringe apenas à sala de aula do ponto de vista físico, e sim a uma série de aspectos que definem a forma como se dá o aprendizado, a natureza das interações entre professor e aluno, as expectativas de aprendizagem, os materiais curriculares utilizados, o projeto político pedagógico da instituição, os aspectos disciplinares e a dinâmica estabelecida entre o grupo de alunos. Como afirmam Carlson e Daehler (2019), os 
atributos dos alunos são o aspecto mais importante do contexto de aprendizagem e incluem fatores como idade, nível de escolaridade, disposição para o aprendizado, prontidão para o desenvolvimento intelectual, valores e crenças. Um professor qualificado reconhece esses aspectos e procura identificar e contemplar esses atributos no seu ciclo de planejamento, ensino e reflexão.

\section{ASPECTOS METODOLÓGICOS}

O professor participante da pesquisa atua na rede privada de ensino, no ensino médio regular e técnico. Possui bacharelado e licenciatura em Química, com mestrado na área de Química Orgânica. É um professor experiente, com mais de trinta anos na educação básica.

Com relação às propostas de ensino das instituições, denominadas neste trabalho de colégios A e B, destacamos elementos que estão no Projeto Político Pedagógico de ambas. Os distintos contextos de escolas resultam em diferentes interações entre alunos e professor e entre os alunos.

O colégio A declara como filosofia de ensino a formação de cidadãos autônomos, por meio de um ensino interdisciplinar, que conduz o estudante a construir o seu próprio saber. A comunidade local admira a escola, que é tida como uma instituição de excelente qualidade, fato que se observa com facilidade na secretaria do colégio, devido ao grande número de procura por vagas. Trata-se de um colégio pequeno, o que facilita a interação entre alunos, professores e funcionários. O público da escola é heterogêneo, tanto no aspecto sociocultural como no econômico. Essa diversidade torna a sala de aula um ambiente plural.

O colégio B declara como filosofia de ensino a pedagogia de base franciscana, que concilia abordagens pedagógicas inovadoras na busca de um aprendizado dinâmico e que auxilie o seu estudante a desenvolver habilidades essenciais para se inserir na sociedade. Trata-se de um colégio com ótima infraestrutura, porém, a sua grande área, estrutura organizacional e número de pessoas resultam em um maior distanciamento entre funcionários, professores e estudantes, formando um ambiente com pouca interação quando comparado ao colégio A. O público pertence a uma classe social com elevado poder aquisitivo, fato observado no valor das mensalidades, nos vestuários e acessórios utilizados pelos próprios alunos.

Este trabalho, desenvolvido a partir de um recorte do Mestrado feito pelo primeiro autor deste artigo e orientado pelo segundo, resulta de uma pesquisa qualitativa, que usa como abordagem de investigação o estudo de caso, que se caracteriza pelo estudo de um fenômeno e/ou uma situação particular, na qual se considera a complexidade e a especificidade do caso em si. A sua descrição e interpretação exigem, dentre outros aspectos, reflexão e criatividade por parte do pesquisador, uma vez que este não tem o controle das distintas variáveis que interferem no fenômeno em estudo (Mertens, 2015).

Nesta investigação, temos um caso, uma vez que o foco de análise é num professor específico, que atua em duas escolas com propostas muito distintas, utiliza o mesmo material didático de sua autoria em ambas as escolas e ministrou o mesmo conteúdo nos 
dois contextos. Busca-se compreender, com base no MCR do PCK, as mudanças que ocorrem na prática desse professor ao ensinar o mesmo conteúdo para alunos inseridos em contextos escolares distintos usando o mesmo material curricular.

Os dados foram extraídos de planejamentos elaborados pelo professor nos dois colégios, entrevistas, notas de aula, material curricular, respostas ao CoRe e registro audiovisual das aulas. A coleta de dados foi realizada ao longo de aproximadamente sete meses, nos quais foi feito o registro audiovisual de aulas de química nos dois colégios, de sequências didáticas que tratavam do mesmo conteúdo. Neste trabalho, focaremos na sequência de ensino sobre nomenclatura de compostos orgânicos nas duas escolas.

O CoRe é instrumento conhecido na pesquisa de conhecimento de professores (Loughran, Berry, \& Mulhall, 2006; Fernandez, 2015). Ele traz oito questões sobre as principais ideias que o professor apresenta sobre um determinado conteúdo. Esse instrumento documenta o entendimento do professor sobre aspectos particulares do PCK, começando pela declaração das ideias centrais ao redor do assunto específico; a importância de que os estudantes as adquiram; o conhecimento das concepções alternativas dos estudantes; os pontos conhecidos de confusão para eles; as estratégias didáticas empregadas para apresentar as ideias e as formas condizentes de avaliá-las (Loughran et al., 2001).

A partir do registro audiovisual e da seleção dos episódios, foi realizada a reflexão estimulada em duas oportunidades distintas (uma para cada instituição de ensino), na forma de entrevistas, com cerca de duas horas cada, na qual o professor assistia aos trechos selecionados no intuito de resgatar a sequência trabalhada em ambas as instituições. A cada trecho, o professor respondia às perguntas presentes no CoRe, para que fosse possível, ao final dessa etapa, acessar o seu PCK referente ao conteúdo lecionado. A análise das entrevistas foi realizada com base nas respostas às questões do CoRe, ou seja, buscou-se nas colocações do professor a identificação de elementos que revelassem o entendimento sobre o conteúdo, sua importância, as dificuldades dos estudantes e as estratégias adotadas para o ensino. Essas análises foram relacionadas ao PCK pessoal do professor, uma vez que o instrumento foi respondido individualmente.

O planejamento do professor e o material curricular usado nas duas escolas e que foi escrito por ele foram também elementos relacionados ao PCK pessoal do professor. As transcrições dos registros audiovisuais das aulas (cerca de 7 horas no colégio A e 5,5 horas no colégio B) são elementos para o acesso ao PCK em ação do professor investigado. As reflexões vídeo estimuladas foram também utilizadas na compreensão de elementos do PCK pessoal do professor.

As aulas foram gravadas, transcritas e foram selecionados para análise de episódios característicos, nos quais o professor ensinou o mesmo conteúdo e fez o uso do mesmo material curricular em ambas as escolas. Nesse material, foi possível acessar o PCK em ação do professor e como o mesmo era afetado pelos contextos distintos. Tendo em vista os episódios selecionados, lançou-se também uso da ferramenta analítica proposta por Mortimer e Scott (2002) de interações discursivas. Tal ferramenta pode trazer argumentos para a contribuição do contexto no PCK em ação do professor. O primeiro autor deste trabalhou realizou as análises das situações de ensino a partir da ferramenta análitica e, para garantir maior confiabilidade em sua interpretação, os 
resultados foram debatidos dentro do grupo de pesquisa. $\mathrm{O}$ uso da ferramenta analítica de Mortimer e Scott (2002) se justifica para compreender como a dinâmica da sala de aula se altera nas duas escolas.

A estrutura analítica dessa ferramenta de interações discursivas é baseada em cinco aspectos inter-relacionados, dos quais utilizamos três: abordagem comunicativa, intenções do professor e padrões de interação. A abordagem comunicativa é estruturada em torno de duas dimensões - a primeira corresponde ao tipo de discurso (dialógico e de autoridade) e a segunda ao tipo de interação que se estabelece (interativo e nãointerativo). Em um discurso dialógico, existe mais de uma voz, ou seja, o professor considera as concepções do aluno e procura contemplar o seu ponto de vista nas discussões que são realizadas em sala de aula. No outro extremo - de autoridade -, o professor considera a voz do aluno, no entanto, o seu ponto de vista não é considerado para o desenrolar das ideias científicas. A segunda dimensão - interativo e não interativo - considera os tipos de interações que ocorrem em sala. Quando professor e alunos alternam turnos de fala, temos um discurso interativo, ao passo que, quando não existe alternância de turnos, o discurso é considerado não-interativo. A combinação entre essas duas dimensões resulta em quatro classes de abordagem: interativo/dialógico; não-interativo-dialógico; interativo/de autoridade e nãointerativo/de autoridade. As intenções do professor, por sua vez, permitem identificar os objetivos do professor ao desenvolver e aplicar o seu plano de aula, sendo constituídas por: criar um problema; explorar a visão dos estudantes; introduzir e desenvolver a história científica; guiar no trabalho de internalização das ideias científicas; guiar na aplicação das ideias científicas e na ampliação de seu uso; e manter a narrativa, sustentando o desenrolar da história científica. Assim, nos episódios selecionados das aulas gravadas e transcritas, foram analisados os padrões de interação que emergiram na medida em que professor e alunos alternam turnos de fala na sala de aula. Destacam-se alguns exemplos, como I-R-A (Iniciação do professor - Resposta do aluno - Avaliação do professor), I-R-P (Iniciação do professor - Resposta do aluno Permitir o prosseguimento da fala do aluno) e I-R-F (Iniciação do professor - Resposta do aluno - Feedback para que o aluno elabore um pouco mais a sua fala).

Por fim, com base no MCR, analisamos o material que compõe o corpus da pesquisa e estabelecemos correlações de como o contexto de aprendizagem exerce influência na forma de o professor ensinar, mais especificamente, como os domínios de seu PCK pessoal se traduzem em diferentes PCK em ação ao ensinar o mesmo conteúdo em escolas diferentes.

\section{RESULTADOS E DISCUSSÃO}

\section{Análise do CoRe sobre nomenclatura de compostos orgânicos}

O CoRe mostra duas preocupações centrais que influenciam a forma de ensino do professor. A primeira é trabalhar em sala de aula as dificuldades que, em geral, os estudantes apresentam ao nomear um composto orgânico, e a segunda reside em trabalhar com eles a linha de raciocínio que devem utilizar para nomear um determinado composto, evitando, assim, uma tendência no ensino desse tema, que é a preocupação em decorar as regras de nomenclatura. $\mathrm{O}$ conhecimento das dificuldades dos alunos 
influencia a sua estratégia de ensino, pois os exemplos que o professor escolheu para trabalhar esse tema levam em conta esse fato.

[...] dando aula você percebe, os alunos sempre cometem os mesmos erros, por isso, já tenho os exemplos adequados para evitar isso. Quando um aluno me faz uma pergunta, eu já sei aonde ele quer chegar. Os exemplos são pensados para evitar os erros comuns dos alunos (Fala do professor na entrevista).

O professor, a cada exemplo dado, trabalha com os estudantes as ideias relacionadas ao tema, permitindo, como estratégia de compreensão, que consultem a tabela disponível no material com as terminologias e regras.

[...] não precisa decorar, tem que saber consultar, usar a lógica para montar a estrutura (Fala do professor na entrevista).

Essas preocupações centrais dialogam com algumas camadas de conhecimento presentes no MCR. A escolha de exemplos adequados para suprir eventuais dificuldades e erros que geralmente os alunos cometem são aspectos do PCK pessoal do professor, afinal, trata-se de uma destreza desenvolvida em função de sua experiência. $\mathrm{O}$ fato do professor não pautar a memorização das regras dialoga com o PCK coletivo canônico, pois é notório o esforço por parte de educadores químicos e professores em atribuir sentido ao que é ensinado, de modo a compreender os diferentes aspectos da linguagem química. As preocupações centrais no ensino desse conteúdo são colocadas em prática em ambas as instituições de ensino, porém, a forma como o professor planeja, ensina e reflete na ação em sala de aula são distintas.

\section{Análise da sequência didática sobre nomenclatura de compostos orgânicos}

Para facilitar a socialização das análises e o seu entendimento, dividimos em quatro episódios a aula que teve como temática nomenclatura de cadeias ramificadas. Como estratégia para alcançar seu objetivo - nomear cadeias ramificadas -, o professor inicialmente lança o tema da aula para os estudantes e desenha na lousa sete estruturas distintas (Figura 2).

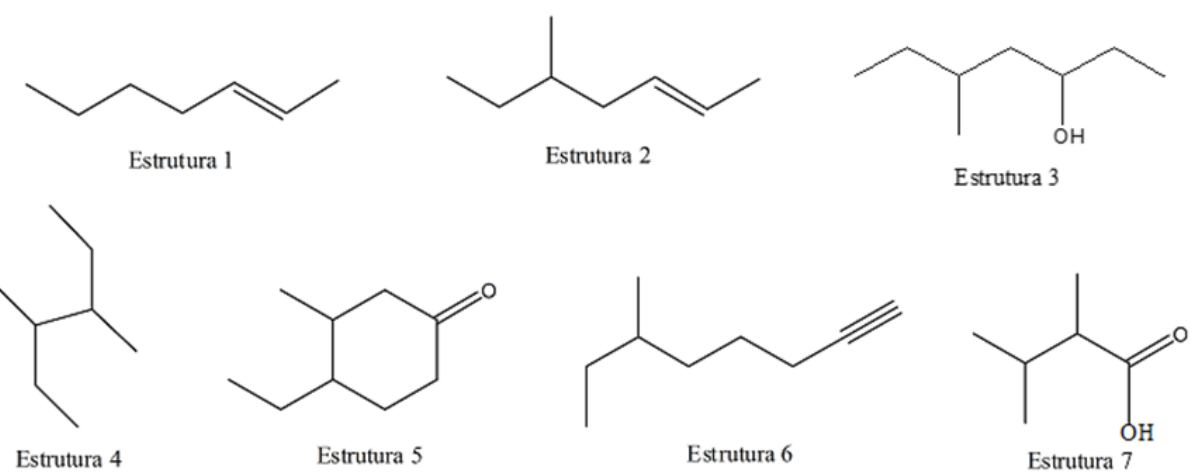

Figura 2: Cadeias carbônicas em linha desenhadas na lousa pelo professor.

Neste primeiro momento, em ambas as instituições, o professor inicia as discussões resgatando uma ideia desenvolvida anteriormente, nomear uma cadeia não 
ramificada (estrutura 1). Desse modo, possibilita que o estudante aprenda os conceitos do novo assunto e destaca similaridades e diferenças entre uma cadeia ramificada e uma cadeia não ramificada. A seguir, apresentamos na figura 3 trechos desse episódio.

\begin{tabular}{|l|l|}
\hline \multicolumn{1}{|c|}{ Colégio A } & \multicolumn{1}{c|}{ Colégio B } \\
\hline (5). P: Gente, é o seguinte... se a gente fosse & (3). P: Se o cara fosse nomear essa estrutura \\
retomar o nome dessa estrutura aqui & (estrutura 1), como você faria? Conseguem \\
(estrutura 1), qual seria? (I) & fazer sem a tabela? (I) \\
(6). P: But... & (4). Alunos: hept...como é mesmo? \\
(7). Alunos: Não, hept... (R) & (5). A: 2-heptano (R) \\
(8). P: Isso, hept... (A) & (6). P: Isso, mas não é heptano, quero dizer, \\
(9). Alunos: 2-eno... & (7). A: É “en". \\
(10). P: De onde vem o hept? (I) & (8). P: Isso, psiu.... \\
(11). A: Sete carbonos (R) & (9). P: Hept... \\
(12). P: Isso. (A) & (10). Alunos: 2... \\
(13). Alunos: O 2 é a posição da dupla... & (11). P + Alunos: Hept-2-eno \\
(14). P: Isso, o "en" significa a própria & \\
dupla... e o "o" é a função, no caso,, & (12). P: Ok...Psiu.... \\
hidrocarboneto. &
\end{tabular}

Figura 3: Nomenclatura de Compostos Orgânicos - Episódio 1/4 - Nomeando a estrutura 1.

Nesse episódio, o professor tem a intenção de criar um problema, no intuito de engajar os estudantes intelectualmente no desenvolvimento da 'história científica'. $\mathrm{O}$ professor mantém a mesma estratégia em ambas as escolas, conduz o exercício de nomear a estrutura 1 por meio de uma sequência de perguntas e respostas, através de uma abordagem do tipo interativo/de autoridade, estabelecendo como padrão de interação a tríade I-R-A. Nos turnos de fala, o professor realiza intervenções, de modo a rever o progresso da 'história científica', recapitulando ideias desenvolvidas na aula anterior (Mortimer, \& Scott, 2002).

Apesar de o professor não trazer algo novo, os estudantes do colégio B apresentam algumas dificuldades em nomear a estrutura, por exemplo, no uso do infixo adequado para nomear um composto que apresenta dupla ligação (turno 6), e a necessidade de consulta de uma tabela com as regras de nomenclatura (turno 3). Além dessa observação, durante o diálogo, o professor precisa pedir silêncio (turnos 8 e 12), coisa que não se observa na sequência do colégio A. Ao ser questionado acerca desses fatos, o professor explica que isso não se deve à natureza do tema e sim ao fato dos estudantes do colégio B apresentarem maior dificuldade, exigindo da sua parte a retomada de conceitos já estudados anteriormente.

Os alunos do colégio B apresentam maior dificuldade, isso faz com que eu tenha que fazer muitas retomadas, dando muitas respostas prontas. Os alunos do colégio A estudam mais, têm mais prontidão em aula, fazem mais exercícios, isso acaba fazendo diferença (Fala do professor na entrevista).

A interpretação desse episódio, com base no MCR, permite compreender como o professor mobiliza sua base de conhecimento profissional para o ensino, visualmente representada na camada mais externa do modelo. $\mathrm{O}$ episódio evidencia, em relação ao conhecimento do conteúdo específico, que o professor apresenta domínio do tema, mostra segurança ao interagir com os estudantes e ao apontar os equívocos cometidos 
ao nomear a estrutura 1 (colégio A: turno 7; colégio B: turno 6). Com relação à gestão da sala de aula, destaca-se o fato do professor, em pouco tempo, trazer os estudantes para discutirem o assunto proposto e mostrar um cuidado com a questão disciplinar, fato perceptível no colégio B (turnos 8 e 12) ao chamar atenção daqueles que se dispersam já no início da aula. O episódio também evidencia algumas diferenças em como ocorre a atuação do professor em aula. No colégio B, o professor complementa as ideias dos estudantes (turno 11), pois é de seu conhecimento que eles apresentam maiores dificuldades em relação ao domínio do conteúdo, como o próprio professor colocou durante a entrevista. De modo distinto, no colégio $\mathrm{A}$, o professor dá mais voz aos alunos e aparenta ter maior confiança de que eles chegarão no resultado.

Na estrutura 2, o professor pede aos estudantes do colégio A para nomearem a cadeia como se fosse uma cadeia normal, escondendo a ramificação na lousa com a mão. A seguir, pede a eles que montem a cadeia a partir do nome dado. Os alunos percebem que esta apresenta diferença em relação à estrutura 2, então, o professor inicia a discussão das ideias centrais desse tema, cadeia principal e ramificação (Figura 4).

\begin{tabular}{|c|c|}
\hline Colégio A & Colégio B \\
\hline $\begin{array}{l}\text { (15) P: Se a gente for repetir a mesma ideia no } \\
\text { outro caso (estrutura 2), como é que você } \\
\text { chamaria? (I) } \\
\text { (17). A: Oct-2-eno (R) } \\
\text { (19). P: Oct-2-eno. Agora, se eu tampasse isso } \\
\text { aqui (a estrutura) e o cara pegasse esse nome } \\
\text { (nome da estrutura) para transformar em } \\
\text { molécula, ele chegava nisso daqui (aponta para a } \\
\text { estrutura desenhada na lousa)? (I) } \\
\text { (20). Alunos: Não. (R) } \\
\text { (22). P: Porque você ia imaginar que essa } \\
\text { molécula está numa linha reta, concorda? (I) } \\
\text { (23). A: Claro (R) } \\
\text { (24). P: Então, não pode ser só isso. Na verdade, } \\
\text { eu vou começar a mexer agora com esse tipo de } \\
\text { estrutura aqui (sublinha a palavra "ramificadas"). } \\
\text { (A) } \\
\text { (25). P: O que é uma cadeia ramificada? (I) } \\
\text { (26). A: Tem raiz... (R) } \\
\text { (27). P: Exatamente, ela começa como se fosse } \\
\text { uma árvore, podem aparecer galhos no meio. } \\
\text { Essa ideia de ramificação são carbonos fora... (A) } \\
\text { (28). A: da linha. } \\
\text { (29). P: Isso, e essa linha eu vou chamar de cadeia } \\
\text { principal. Então vai começar a aparecer coisa } \\
\text { nova aí. A gente não tinha discutido até agora, } \\
\text { mas vamos começar a mexer com moléculas que } \\
\text { são maiores, são mais complexas e vão ter } \\
\text { carbonos fora da linha central. } \\
\text { (30). P: A gente mexeu até esse momento, com } \\
\text { moléculas menores, geralmente moléculas mais } \\
\text { simples, com uma função só. Então, vai começar } \\
\text { a misturar as funções, vai começar a aparecer }\end{array}$ & $\begin{array}{l}\text { (33). P: Vamos utilizar essas ideias naquele } \\
\text { exemplo ali (estrutura 2). A cadeia principal } \\
\text { dessa estrutura aqui é essa linha aqui (pinta de } \\
\text { laranja com o giz). Essa linha laranja representa a } \\
\text { cadeia principal dessa molécula. Como assim? } \\
\text { (34). P: É a cadeia maior que você conseguiu } \\
\text { riscar. Ela não pode voltar por cima dela própria. } \\
\text { Então esse carbono da ramificação vai ficar de } \\
\text { fora. E você marcou a insaturação, ela faz parte } \\
\text { da cadeia principal. } \\
\text { (36). P: Qual a cadeia principal disso (estrutura } \\
\text { 1)? (I) } \\
\text { (37). A: Ah, é tudo... (R) } \\
\text { (38). P: É a cadeia inteira. Se o cara for lembrar o } \\
\text { que caiu na prova, o cara vai lembrar que era a } \\
\text { cadeia inteira, não tinha carbono que ficava de } \\
\text { fora. (A) } \\
\text { (39). P: Você consegue riscar todos os carbonos } \\
\text { aqui (estrutura 3)? (I) } \\
\text { (40). A: Não. (R) } \\
\text { (41). P: Então, vai ficar coisa de fora. (A) No } \\
\text { caso, vai ficar um carbono de fora. Qual é a } \\
\text { principal disso? (I) } \\
\text { (42). A: É a de baixo. (R) } \\
\text { (43). P: Isso, é essa mesmo. (A) } \\
\text { (50). A: dois... } \\
\text { (51). P: Então, esse carbono aqui de fora } \\
\text { (estrutura 2) é um CH } 3 \text {, certo? Ele é chamado de } \\
\text { ramificação ou radical. } \\
\text { (52). P: Então repara, gente, pegando a tabela de } \\
\text { orgânica, no final da apostila... pega aí... } \\
\text { (55). A: Ah... achei... metil. } \\
\text { (56). P: Isso, metil. Como é que vai ficar agora? }\end{array}$ \\
\hline
\end{tabular}


carbono fora da cadeia principal, assim por (58). P: Tá vendo um $\mathrm{CH}_{3}$ nela? É para ver quem diante.

(31). P: Então vai aparecer um conceito, que é na cadeia principal, isso é chamado de isso daqui (escreve na lousa): Cadeia principal. ramificação.

Figura 4: Nomenclatura de Compostos Orgânicos - Episódio 2/4 - Nomeando a estrutura 2.

A intenção do professor neste e nos episódios a seguir é guiar os estudantes no trabalho com as ideias científicas, dando suporte ao processo de internalização, uma vez que explora ideias, formula perguntas e considera opiniões para chegar a um ponto de vista específico, no caso, cadeia principal e ramificação (abordagem: interativo/dialógico-interativo/de autoridade), seguindo os padrões de interação I-R-A e I-R-P (Mortimer, \& Scott, 2002). As intervenções do professor são realizadas de modo a dar forma aos significados, uma vez que, ao introduzir um novo termo - cadeias ramificadas -, o professor procura mostrar as diferenças e compartilha com a sala essas ideias.

Diferentemente do colégio A, no qual o professor explora a visão dos estudantes para introduzir o conceito (turno 25), no colégio B, ele apenas relembra o conceito de cadeia principal e exemplifica utilizando as estruturas 1, 3 e 4. Nesse episódio, fica evidente a mudança na estratégia de ensino, o professor apresenta os conceitos necessários para nomear a estrutura 2, não permitindo que os estudantes participem desse processo de forma mais ativa, visto que seu padrão de interação é I-R-A, como se observa na figura 4.

A intenção do professor nesse episódio, ao trabalhar o conceito de cadeia ramificada, mostra uma preocupação em disponibilizar as ideias conceituais (introduzindo e desenvolvendo a 'história científica'), diferente da maneira que ocorreu no colégio A, onde professor e estudantes, de forma dialogada, partem da natureza da cadeia carbônica para discutir o conceito de cadeia principal.

Ao se observar a forma como interage com os estudantes no colégio B, nota-se o tipo de abordagem (interativo/de autoridade) realizada pelo professor. E nota-se, ainda, nos turnos, as retomadas que ele precisa realizar para chegar ao conceito. Ele também recorre a tabelas para consulta à ramificação, além de usar a prova como elemento de “estímulo" à aprendizagem (turno 38).

Ao ser questionado acerca dessas diferenças, o professor coloca a questão disciplinar como principal fato para conduzir a aula de forma distinta:

A questão disciplinar... O pessoal do colégio A é mais focado em relação aos alunos do colégio B. Tem sala que sou obrigado a conduzir todo o processo. No A, estava mais confiante que os alunos iam fazer, ao passo que, no B, preciso coordenar as ações, sempre chamando a atenção (Fala do professor na entrevista).

Neste episódio, percebe-se que o professor lança mão de uma estratégia interessante ao nomear a cadeia ramificada como se fosse linear (cadeia normal), no intuito de tornar o novo conceito acessível. O conhecimento dos alunos e o contexto de aprendizagem destacam-se neste episódio, visto que a modificação de estratégia leva em conta as características dos estudantes, que no colégio $\mathrm{B}$, devido à indisciplina e dispersão, faz com que o professor transmita um maior número de informações, no 
intuito de conduzir a aula minimizando os problemas disciplinares. Além disso, no colégio $\mathrm{B}$, a prova é usada como moeda de troca para que os alunos prestem atenção à explicação.

Para as estruturas 3 e 4, o professor solicita aos estudantes do colégio A que tentem nomeá-las. A partir desse momento, caminha pela sala de aula, verificando o trabalho e esclarecendo dúvidas. Da mesma forma como ocorreu na estrutura 2, ele estabelece uma abordagem centrada na exploração das ideias dos estudantes e no diálogo com eles para a construção de significados. Após este momento, desenvolve as ideias centrais referente às estruturas 3 e 4, conforme mostra a figura 5.

No colégio A, o professor utiliza uma abordagem do tipo interativo/de autoridade, como nos turnos 159 a 163, em que os estudantes utilizam seus conhecimentos para responder do ponto de vista científico como numerar a cadeia da estrutura 4, estabelecendo padrões de interação do tipo I-R-A e I-R-P. A abordagem interativo/de autoridade é a que prevalece nesse episódio, como pode ser observado nos turnos de 133 a 145, em que o professor conduz a turma por meio de perguntas e respostas, estabelecendo um padrão de interação do tipo I-R-A (Mortimer, \& Scott, 2002). As suas intervenções procuram tornar os significados disponíveis para toda classe.

No colégio B, para nomear as estruturas 3 e 4, o professor conduz os estudantes com uma sequência de perguntas e respostas, estabelecendo, assim, uma abordagem do tipo interativo/de autoridade. Diferentemente do que ocorreu no colégio A, não há o estabelecimento de um diálogo que envolva exploração de ideias, o que pode dificultar a aprendizagem dos conceitos, ou seja, não há espaço para o professor explorar as ideias dos estudantes. Nesse episódio no colégio B, o professor faz uso de cores diferentes de giz para enfatizar a cadeia principal. Além disso, transparece nesse trecho o interesse dos estudantes pela avaliação e seus resultados (turno 109). Essa pergunta é feita no meio da explicação do exercício, sem nenhuma relação com a atividade que estava sendo realizada no momento. As intervenções do professor procuram tornar os significados disponíveis para toda classe (Mortimer, \& Scott, 2002). 


\begin{tabular}{|c|c|}
\hline Colégio A & Colégio B \\
\hline $\begin{array}{l}\text { (133). P: Como ficou a principal disso (estrutura } \\
\text { 3)? (I) } \\
\text { (134). A: É a linha... (R) } \\
\text { (135). P: Certo... (A) Qual a função disso daqui? } \\
\text { (I) } \\
\text { (136). A: Álcool. (R) } \\
\text { (137). P: Por onde vou começar a numeração? (P) } \\
\text { (138). A: Prá lá, pela direita. (R) } \\
\text { (139). P: Isso, próximo do grupo funcional, vou } \\
\text { numerar. (A) } \\
\text { (140). P: E agora, o que é isso aqui? (aponta para } \\
\text { o radical) (I) } \\
\text { (141). A: É metil. (R) } \\
\text { (142). P: Isso, então ficaria... como? Esquecendo } \\
\text { o metil por enquanto? (A)/(I) } \\
\text { (143). A: metil-3-ol. (R) } \\
\text { (144). P: Calma, calma, sem o metil... (A) } \\
\text { (145). A: hept... } \\
\text { (146). P + A: Heptan-3-ol. } \\
\text { (147). P: Tudo bem? E o metil, como faço? (I) } \\
\text { (148). A: 5-metil... (R) } \\
\text { (149). P: Isso, 5-metil-heptan-3-ol. (A) } \\
\text { (154). P: Tudo bem, gente. Como fica a principal } \\
\text { dessa (estrutura 4)? (I) } \\
\text { (155). A: Começa de cima... desce... (R) } \\
\text { (156). P: Isso, a principal... (P) } \\
\text { (157). A: Esquerda... (R) } \\
\text { (158). P: Isso, exatamente, é a maior. (A) } \\
\text { (159). P: Numeração? (I) } \\
\text { (160). A: Começa de baixo... (R) } \\
\text { (161). P: Podemos começar pela de cima? (P) } \\
\text { (162). A: Ah, tanto faz! (R) } \\
\text { (163). P: Isso, não faz diferença. Pode começar a } \\
\text { numerar por cima ou por baixo. Reparem que eu } \\
\text { tenho dois metil... no carbono três e no quatro. O } \\
\text { pessoal, de modo geral, montou certo pelo o que } \\
\text { eu vi, esqueceu apenas de uma coisinha... (A) } \\
\text { (164). A: Ah... 3,4 metil... } \\
\text { (165). P: Não, isso não.... foi o “di”. Vejam... 3,4- } \\
\text { dimetil-hexano. }\end{array}$ & $\begin{array}{l}\text { (81). P: Então, terceiro caso (estrutura 3). Que } \\
\text { função é essa daqui, gente? } \\
\text { (82). A: Álcool. } \\
\text { (83). P: Qual o carbono mais importante dessa } \\
\text { cadeia? } \\
\text { (85). P: É o carbono do álcool, esse carbono é o } \\
\text { mais importante. Portanto, a numeração vai } \\
\text { começar na ponta mais próxima dele. A cadeia } \\
\text { principal tem que passar por ele. Qual seria então? } \\
\text { (I) } \\
\text { (86). A: É a reta. (R) } \\
\text { (87). P: Isso, é essa mesmo. Para numerar, tem que } \\
\text { ser a ponta próxima do grupo funcional. E aí } \\
\text { ficaria assim. Sobrou um carbono fora, que } \\
\text { ramificação é essa? (A) } \\
\text { (88). A: Metil. } \\
\text { (89). P: Isso. Esquece um pouco a ramificação, dá } \\
\text { o nome sem a ramificação, conta então só a parte } \\
\text { laranja. } \\
\text { (90). A: 7-heptano. } \\
\text { (91). P: Quase isso, heptan.... } \\
\text { (92). A: nol... } \\
\text { (93). P: Isso, isso mesmo. Sendo álcool a } \\
\text { terminação, é ol. Falta uma coisa nesse nome aí... } \\
\text { (I) } \\
\text { (101). P: Então fica 5-metil-heptan-3-ol. } \\
\text { (102). P: No quarto caso (estrutura 4), como fica... } \\
\text { a função? (I) } \\
\text { (103). Alunos: Hidrocarboneto. (R) } \\
\text { (104). P: Isso, hidrocarboneto. A cadeia principal } \\
\text { seria essa (pinta em laranja), a gente já falou isso } \\
\text { aí. Se fosse numerar, por qual ponta você } \\
\text { começaria? (A)/(I) } \\
\text { (105). A: De cima. (R) } \\
\text { (106). A: Tanto faz... (R) } \\
\text { (107). P: Tanto faz, porque dá na mesma. (A) } \\
\text { (108). P: Aluno, vira para frente, acompanha. } \\
\text { (109). A: Professor, você vai devolver as provas } \\
\text { de recuperação? } \\
\text { (110). P: Eu vou mostrar, mas não agora. } \\
\text { (112). A: Vai ser dimetil. } \\
\text { (113). P: Isso mesmo, como fica o nome só da } \\
\text { parte laranja? } \\
\text { (114). A: Hexano. } \\
\text { (116). A: Professor, fica 3,4-dimetil...hexano. }\end{array}$ \\
\hline
\end{tabular}

Figura 5: Nomenclatura de Compostos Orgânicos - Episódio 3/4 - Nomeando a estrutura 3 e 4.

Nesse episódio, percebe-se que os alunos e o contexto de aprendizagem influenciam no PCK em ação do professor, que é informado pelo seu PCK pessoal. Há uma preocupação com a gestão da aula, que, devido ao aspecto disciplinar, faz com que 
ele opte por estratégias distintas que refletem na maneira como conduz a aula e realiza as ações. No colégio A, o professor valoriza o papel do estudante e deixa-o responsável pela condução do processo, na medida em que dá mais tempo e abertura para que tente, para que discuta com colegas, facilitando aquisição das ideias que estão sendo trabalhadas. Ao optar pelo maior protagonismo do aluno no processo, ele lança mão de habilidades vinculadas ao seu PCK pessoal, que, por sua vez, reflete de forma direta no PCK em ação. A troca dinâmica entre estas camadas de conhecimento permite ao professor lançar mão de diferentes estratégias para alcançar seu objetivo, no caso deste episódio, deixando um momento da aula para os estudantes do colégio A trabalharem em grupo, ao passo que centraliza as ações no colégio B. Além disso, dá mais tempo e deixa os alunos no colégio A mais soltos, pois confia que chegarão ao resultado desejado, enquanto no colégio B o professor centraliza as ações nele. No colégio A, os alunos mostram-se interessados na atividade e querem chegar no resultado, enquanto no colégio B os estudantes estão mais dispersos e se distraem mais facilmente. Depois de explicar as ideias centrais para nomear as estruturas 3 e 4 , o professor pede aos alunos do colégio A que nomeiem as estruturas 5 e 6 . Após um breve período de discussão entre os estudantes, ele inicia na lousa o fechamento, estabelecendo um padrão de interação do tipo I-R-A e I-R-P (Figura 7).

No decorrer da discussão, tamanho o envolvimento e interesse pelo assunto, o professor sente a necessidade de desenhar uma nova estrutura (estrutura 8) na lousa, para verificar se os estudantes conseguem identificar a cadeia principal (Figura 6).

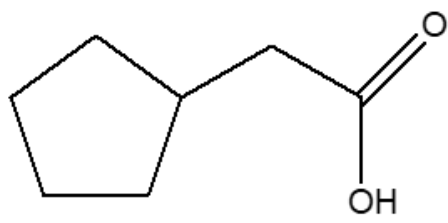

\section{Estrutura 8}

Figura 6: Estrutura de cadeia carbônica em linha. 


\begin{tabular}{|c|c|}
\hline Colégio A & Colégio B \\
\hline $\begin{array}{l}\text { (177). P: Agora, e se eu tivesse isso (estrutura } \\
\text { 8), quem é a principal? (I) } \\
\text { (178). P: É a fechada ou a aberta? (R) } \\
\text { (179). A: Aberta... (A) } \\
\text { (199). P: Porque ela só pode ser a primeira, pois } \\
\text { a cadeia é fechada e contém o grupo funcional. } \\
\text { O professor avisa que a coordenadora irá } \\
\text { entregar os boletins. } \\
\text { (200). A: Ah, não...faz o outro antes... } \\
\text { (201). P: Tá, como será a cadeia principal } \\
\text { (estrutura 6)? } \\
\text { (202). A: Traça a linha... } \\
\text { (203). P: Isso, e desce... } \\
\text { (204). A: Por que desce? } \\
\text { (205). A: Porque é a maior... } \\
\text { (206). P: Isso... a principal tem o maior número } \\
\text { de carbonos. } \\
\text { (207). P: Quem é o segundo carbono? (I) } \\
\text { (208). A: Esse perto da tripla... (R) } \\
\text { (215). P: Como fica o nome disso daí? (I) } \\
\text { (216). A: Fica 6-metil... (R) } \\
\text { (217). P: Isso, 6-metil-oct... (A) } \\
\text { (218). A: Eu coloquei um! } \\
\text { (219). P: Isso, 6-metil-oct-1-ino } \\
\text { (220). P: Pessoal, vamos lá... quero fazer com } \\
\text { vocês esses quatro aqui. } \\
\text { (221). P: Vamos guardar os boletins, pois se } \\
\text { não, não tem aula. } \\
\text { (222). P: Aqui, nessa estrutura, posso numerar a } \\
\text { partir do "o"? } \\
\text { (225). P: Bem, por onde começo a numerar? (I) } \\
\text { (226). A: Pelo carbono do ácido... (R) } \\
\text { (227). P: Isso, esse aqui. E iria para onde? À } \\
\text { esquerda, desce ou segue até o final? (A) } \\
\text { (228). A: Desce... } \\
\text { (257). P: Etil. Como é que fica esse nome? (I) } \\
\text { (258). A: É... etil... (R) } \\
\text { (260). P + A: 2-etil-5-metil-oct-3-en-1ol. (R) }\end{array}$ & $\begin{array}{l}\text { (119). P: A primeira coisa é localizar a função. } \\
\text { Qual é a função dessa molécula? } \\
\text { (120). P: É uma.... cetona. Portanto, o carbono } \\
\text { da função tem que fazer parte da cadeia } \\
\text { principal, não pode ficar de fora. } \\
\text { (121). P: Outra coisa, a cadeia principal ou é } \\
\text { fechada ou aberta, não pode misturar os dois. } \\
\text { (122). Alunos: Falam juntos, não sendo } \\
\text { compreensível o que dizem. } \\
\text { (123). P: Pessoal, psiu... } \\
\text { (124). P: Ou você pega a parte aberta ou a } \\
\text { fechada. } \\
\text { (125). A: Pega a fechada. } \\
\text { (126). P: Exatamente. Se for numerar, quem é o } \\
\text { número 1? (I) } \\
\text { (127). A: O da acetona... (R) } \\
\text { (128). P: Exatamente, quem vai ser o número 2? } \\
\text { (A) } \\
\text { (130). P: Acompanha aqui, aluno. Vocês dois } \\
\text { estão com a apostila aberta? } \\
\text { (131). P: Bem, está aí. Como fica o nome, vocês } \\
\text { fazem ideia? (I) } \\
\text { (132). A: 3-metil-4-etil... (R) } \\
\text { (134). A: É, hexano... (R) } \\
\text { (135). P: Não, sem o ano. (A) } \\
\text { (136). P + A: ciclohexanona. } \\
\text { (140). P: Bem, agora monta esse (estrutura 6), } \\
\text { não fala a resposta alto. Só lembrando uma } \\
\text { coisa, quantos carbonos tem nessa linha? (I) } \\
\text { (141). A: Três. (R) } \\
\text { (142). P: Três, três carbonos, por que não dois? } \\
\text { (P) } \\
\text { (143). A: Tem um ali perto da tripla... (R) } \\
\text { (144). P: Isso mesmo, tem um carbono aqui. (A) } \\
\text { (147). P: Eu vi o de alguns e tem uma coisa aí } \\
\text { que apareceu. Se a pessoa riscar a cadeia } \\
\text { principal errada, obviamente o nome estará } \\
\text { errado. E nesse caso a principal inclui este } \\
\text { carbono? (I) } \\
\text { (148). A: Não. (R) } \\
\text { (149). P: Inclui sim, pois, a cadeia principal tem } \\
\text { que ser a maior possível. Então, como é que fica } \\
\text { esse nome? (A) } \\
\text { (153). P: 6-metil-oct-1-ino } \\
\text { (154). P: Ow, silêncio... }\end{array}$ \\
\hline
\end{tabular}

Figura 7: Nomenclatura de Compostos Orgânicos - Episódio 3/4 - Nomeando a estrutura 5 e 6. 
Ao ser questionado sobre a necessidade de desenhar uma nova estrutura na lousa, o professor responde:

Por causa das perguntas, [...] os alunos do colégio A vão arrancando de mim, quando perguntam, me instigam, e aí eu dou mais. Se as perguntas são simples, acabo ficando no arroz com feijão (Fala do professor na entrevista).

Ao retomar a resolução das estruturas 5 e 6, o professor foi interrompido pela coordenadora, que solicitou um espaço na aula para realizar a entrega dos boletins. Assim que o professor resolveu a estrutura 5, os estudantes pediram para dar sequência, como mostra o trecho extraído da transcrição desse momento da aula (turnos 199 a 201).

Ao ser solicitado para que comentasse acerca da interrupção por parte da coordenadora e o pedido incomum dos estudantes para que ele continuasse a explicação, o professor fez a seguinte colocação:

Quando os alunos fazem sozinhos, eles ficam ansiosos para fazer o resto... se sentem curiosos para fazer o resto. As estruturas têm uma progressão no nível de dificuldade, é como um videogame... eles queriam confrontar as respostas deles com as corretas (Fala do professor na entrevista).

Da mesma forma, ocorre com as estruturas 5 e 6, ele estabelece, principalmente, um padrão de interação do tipo I-R-A, conduzindo a resolução (turnos 202 a 219). Antes de nomear a estrutura 6, o professor pede que a coordenadora realize a entrega dos boletins, o que perturba de certa forma a aula, pois os estudantes ficam agitados e falantes durante e após o recebimento dos mesmos. Ao retomar a aula, pede para que os boletins sejam guardados e, na sequência, restabelece a discussão envolvendo a estrutura 6.

O professor não consegue terminar as discussões acerca da estrutura 7, pois a aula chegou ao fim. As intervenções procuram marcar significados chaves, o que fica evidente ao estabelecer uma sequência de turnos do tipo I-R-A com um estudante para confirmar uma ideia (Mortimer \& Scott, 2002).

No colégio B, o professor coloca na lousa as estruturas 5, 6 e 7. Ele olha para o relógio, encerra a aula sem resolver o último exemplo. Nenhum estudante se manifestou. É perceptível que o professor chama a atenção dos estudantes por várias vezes no colégio B (turnos 123, 130 e 154), eles próprios desviam o foco e a sequência da aula. Isso impossibilita as interações que observamos no colégio A, no qual o professor sente a necessidade de ir além dos conceitos e explorar diversos pontos de vista. A aula em ambas as escolas chegou ao fim sem o professor conseguir discutir a estrutura 7.

Nesse episódio envolvendo as estruturas 5 e 6, destaca-se o seu PCK pessoal, pois, no colégio A, devido aos questionamentos dos estudantes, o professor lança mão de seu repertório para desenhar uma nova estrutura (turno 177), o que enriquece as discussões. Com relação ao conhecimento pedagógico geral, percebe-se um cuidado do professor em ter o estudante de prontidão, fato que marca sua gestão de sala. No colégio A, após a entrega dos boletins, o professor solicita que os estudantes os guardem e prestem atenção (turno 221), ao passo que, no colégio B, ao perceber dispersão, chama atenção (turno 130). Percebe-se que o conhecimento do contexto de aprendizagem proveniente 
de seu PCK pessoal se traduz em um PCK em ação diferenciado nos dois contextos, como ficou marcado no colégio A ao desenhar a estrutura 8.

Pelas observações nas instituições analisadas, o colégio A apresenta uma estrutura menos grandiosa e equipada que o colégio $\mathrm{B}$, e, no entanto, a relação com o conhecimento é favorecida, os estudantes têm a atenção menos dispersa. Por outro lado, os estudantes do colégio B parecem mais dispersos e mostram-se mais ligados a outros aspectos não relacionados com a aula e apresentam respostas mais mecânicas, sem muito envolvimento. O professor justifica tais diferenças por conta do compromisso das instituições com o ensino.

\begin{abstract}
A estrutura da escola influencia, não dá para um professor ser rigoroso e os outros não serem... O colégio precisa funcionar como um todo, no colégio B não funciona, se cobra pouca lição. Uma escola funciona com lição de casa, precisa ser dado, isso faz diferença, no B eu dou lição de classe. Existe um discurso velado para não dar muita lição, apenas eu, matemática e física que ainda dão alguma coisa (Fala do professor na entrevista).
\end{abstract}

No colégio A, existe uma preocupação da escola em integrar, em relacionar os conhecimentos com a vida do estudante, destacando como se aplica esse conhecimento em sua realidade. Já no colégio $\mathrm{B}$, a preocupação reside na promoção de resultados. E, é claro, isso reflete na maneira como os pais lidam com cada instituição. Segundo o professor:

Os pais participam em ambas as escolas, porém, no colégio $\mathrm{B}$, o pai quer saber se o filho vai passar ou não, não aquilo 'vim aqui conhecer o seu trabalho'. No colégio A, você conhece gente da própria área, tem mais troca, os pais daqui valorizam o estudo (Fala do professor na entrevista).

Nas duas escolas, é nítida a diferença de engajamento dos alunos nas aulas. Da mesma forma, há diferenças de propósito das famílias com o ensino para os filhos e também uma diferença na proximidade das relações entre o professor e os alunos, entre os próprios alunos e entre os funcionários, professores e alunos nas duas escolas. E isso parece se refletir na expectativa do professor com seus alunos em ambas as escolas, e, consequentemente, no modo como o professor conduz as atividades propostas. Assim, embora o professor possua obviamente o mesmo PCK pessoal, ele se manifesta de formas distintas em PCK em ação, ensinando o mesmo conteúdo com as mesmas atividades em ambas escolas por conta do conhecimento do contexto da escola e do conhecimento dos alunos e suas dificuldades, além da expectativa dos pais, o que interfere sobremaneira na sua prática pedagógica.

\title{
CONCLUSÕES
}

Neste trabalho, investigamos o ensino de química em contextos escolares distintos, lançando um olhar acerca do que ensina e como ensina um professor de química experiente.

As mudanças observáveis na sala de aula do professor investigado ao lecionar o mesmo conteúdo em contextos distintos estão relacionadas à forma como os colégios lidam com o conhecimento, e isso reflete de maneira direta na ação do professor em sala de aula e, também, na relação dos seus indivíduos com o conhecimento. 
Retomando nossas questões de pesquisa, quando colocamos quais seriam os aspectos da sala de aula a que atribui essas mudanças - primeira questão -, o professor observa que os estudantes do colégio A têm maior propensão ao estudo. Parecem ter um envolvimento com o conhecimento de nível diferente dos estudantes do colégio B, que apresentam maior distanciamento com a matéria e um menor compromisso com o conhecimento.

Nota-se que os estudantes, na medida em que questionam, participam da aula de forma efetiva, conseguem extrair mais do professor. Nas aulas do colégio A, o professor está mais envolvido e mais à vontade com os estudantes do que nas aulas do colégio $\mathrm{B}$. Isso faz com que ofereça mais tempo para a resposta dos alunos e, de alguma forma, acaba conseguindo um resultado melhor. No colégio B, a questão disciplinar afeta o desenvolvimento da aula, visto que o professor fica mais sério, foca na questão disciplinar e centraliza as ações, ao passo que, no colégio A, o professor propicia maior autonomia dos estudantes, como nos momentos em que abre espaço para o trabalho em grupo. Esse comportamento resulta em interações discursivas distintas em ambas as escolas. Esses fatos respondem à segunda questão, que diz respeito à influência dos estudantes na forma de ensinar do professor.

O olhar analítico na forma como o professor ensina em ambos os contextos de aprendizagem, a partir do MCR, evidencia como ele mobiliza diferentes domínios do conhecimento na ação educativa. Dentre estes domínios, destacam-se o contexto de aprendizagem, o PCK pessoal e o PCK em ação. O PCK pessoal desse professor pôde ser revelado pelas respostas ao CoRe, pela reflexão estimulada de vídeos de sua aula, pelo planejamento da aula e material curricular usado. Já seu PCK em ação, transpareceu nos registros audiovisuais, e nos episódios selecionados percebem-se padrões de interações discursivas distintas em ambas as escolas - IRA e IRP no colégio A e IRA no colégio B. Embora ensine o mesmo conteúdo e, teoricamente, da mesma forma, o que se percebe na prática são atuações muito distintas que revelam o conhecimento do professor de seus alunos, suas dificuldades e dos projetos de escola distintos. Assim, o PCK pessoal desse professor se manifestou diferentemente em PCK em ação nas distintas escolas, resultando em padrões de interação diferentes.

Cabe salientar que o uso da ferramenta analítica de Mortimer e Scott (2002) para esse Estudo de Caso apresentou algumas limitações. Apenas o acesso à linguagem verbal não foi suficiente para traduzir de forma mais fidedigna as diferenças entre as interações que ocorrem entre professor e estudantes no colégio A e no colégio B. As notas de aula e o registro audiovisual realizados sugerem que o uso da multimodalidade, como colocam Mortimer e Quadros (2018), seria uma estratégia interessante para entender como outros recursos semióticos além da linguagem verbal, por exemplo, os gestos, entonação e olhar, se articulam na construção de significados na sala de aula.

O PCK pessoal robusto do professor investigado referente ao conteúdo trabalhado, atrelado ao conhecimento dos dois contextos de escolas, de projeto, de função do ensino e de alunos, faz com que o PCK em ação do professor revele facetas distintas em ambos os colégios. No colégio A, o foco está na aprendizagem dos alunos e o professor se esforça para dar desafios e tempo de discussão para os alunos. Por outro lado, no colégio $\mathrm{B}$, a negociação é muito mais pragmática e truncada. Ressalta, nesse contexto, que o importante é ensinar a resolver exercícios que, supostamente, levarão 
os alunos a bons desempenhos em exames externos, atendendo, assim, a uma demanda da escola e dos pais, e que se traduz numa prática pedagógica com algoritmos e com pouco envolvimento dos alunos na própria aprendizagem, o que foi notado nos momentos de indisciplina e nas perguntas fora de contexto. Com o intuito de ter controle maior sobre a situação, o professor dá pouca voz e faz uso de giz colorido com o intuito de enfatizar elementos importantes do conteúdo, de modo que seus alunos foquem no necessário aos seus exames. Assim, em ambos os colégios, o professor mostra-se coerente com suas práticas pedagógicas e revela um PCK em ação condizente com a tradução de seu PCK pessoal adaptado aos contextos.

A adoção do MCR como modelo teórico para as análises contempladas neste trabalho soma-se aos esforços do campo em utilizar o conceito de PCK de forma mais clara e coerente. Acreditamos que este é um modelo frutífero para subsidiar propostas voltadas para o desenvolvimento profissional de professores, tanto na formação inicial como continuada.

Dentre as contribuições deste trabalho para esse fim, destacamos que o uso do MCR, por um lado, permite ter um olhar mais atento ao seu processo de reflexão na e sobre a ação, uma vez que permite analisar como se dá a mobilização de seus conhecimentos do PCK pessoal para o PCK em ação. Esse tipo de discussão realizada no âmbito coletivo, entre seus pares, favorece o compartilhamento de experiências e o alinhamento de estratégias de ensino de forma cooperativa de modo a favorecer o aprendizado dos estudantes. Por outro lado, o uso do MCR por parte de pesquisadores da área de ensino de forma dialogada com professores auxilia na ampliação e no desenvolvimento de seus conhecimentos profissionais.

\section{AGRADECIMENTOS}

Os autores agradecem a participação do professor investigado, às escolas e aos alunos. Agradecem também o apoio financeiro da Fundação de Pesquisa do Estado de São Paulo (FAPESP), Processo \#2013/07937-8, e do Conselho Nacional de Desenvolvimento Científico e Tecnológico (CNPq), Processos \#431016/2016-0 e \#312911/2018-1.

\section{REFERÊNCIAS}

Abell, S. K. Research on science teacher knowledge. In: S.K. Abell \& N.G. Lederman (Eds.), Handbook of Research on Science Education (pp. 1105-1149). New York: Routledge. 2007.

Abell, S. K. Twenty years later: Does pedagogical content knowledge remain a useful idea? International Journal of Science Education, London, 30(10), 1405-1416. 2008. <https://doi.org/10.1080/09500690802187041>.

Baumert, J., Kunter, M., Blum, W., Brunner, M., Voss, T., Jordan, A., \& Tsai, Y. Teachers' mathematical knowledge, cognitive activation in the classroom, and student 
progress. American Educational Research Journal, 47, 133-180. 2010. <https://doi.org/10.3102/0002831209345157>.

Carlson, J., \& Daehler, K. R. The refined consensus model of pedagogical content knowledge in science education. In: A. Hume,; R. Cooper, \& A. Borowski. Repositioning Pedagogical Content Knowledge in Teachers' Knowledge for Teaching Science (pp. 77-92). Singapura: Springer. 2019.

Fernandez, C. PCK - Conhecimento Pedagógico do Conteúdo: perspectivas e possibilidades para a formação de professores. In: VIII Encontro Nacional de Pesquisa em Educação em Ciências, 2011, Campinas. Atas do VIII Encontro Nacional de Pesquisa em Educação em Ciências. Rio de Janeiro: UFRJ, 2011. v. 1. p. 1-12.

Fernandez, C. Revisitando a Base de Conhecimentos e o Conhecimento Pedagógico do Conteúdo (PCK) de professores de ciências. Ensaio: Pesquisa em Educação em Ciências (Online), 17, 500-528. 2015. <https://doi.org/10.1590/198321172015170211>.

Fernandez, C., \& Goes, L. F. Conhecimento pedagógico do conteúdo: estado da arte no ensino de ciências e matemática. In: A. Garritz, S. F. D. Rosales, \& M. G. Lorenzo. (Orgs.). Conocimiento Didáctico del Contenido. Una perspectiva Iberoamericana (pp. 65-99). 1ed.Saarbrücken, Alemania: Editorial Académica Española. 2014.

Friedrichsen, P., Driel, J. H. V., \& Abell, S. K. Taking a closer look at science teaching orientations. Science Education, 95(2), 358-376. 2011. $\langle$ https://doi.org/10.1002/sce.20428>.

Gess-Newsome, J. A model of teacher professional knowledge and skill including PCK. In A. Berry, P. Friedrichsen, \& J. Loughran (Eds.), Re-examinig Pedagogical Content Knowledge in Science Education (pp. 28-42). New York: Routledge, 2015.

Grossman, P. L. The making of a teacher: teacher and teacher education. New York: Teachers College Press. 1990.

Helmes, J., \& Stokes, L. A meeting of minds around Pedagogical Content Knowledge: designing an international PCK summit for professional, community, and field development. 2013. Disponível em: <http://www.inverness-research.org/reports/201305_Rpt-PCK-Summit-Eval-final_03-2013.pdf>. Acesso em: 21 mar. 2021.

Hume, A., Cooper, R., \& Borowski, A. Repositioning pedagogical content knowledge in teachers' knowledge for teaching science. Singapura: Springer. 2019.

Kind, V. Pedagogical content knowledge in science education: perspectives and potential for progress. Studies in Science Education, 45(2), 169-204. 2009. <https://doi.org/10.1080/03057260903142285>.

Loughran, J. J., Milroy, P., Berry, A., Gunstone, R. F., \& Mulhall, P. Documenting Science Teachers Pedagogical Content Knowledge through PaP-eRs. Research in Science Education, 31, 289-307. 2001. <https://doi.org/10.1023/A:1013124409567>. 
Loughran, J., Berry, A., \& Mulhall, P. Understanding and developing science teachers'pedagogical content knowledge. Rotterdam: Sense Publishers, 2006.

Magnusson, S., Krajcik, L., \& Borko, H. Nature, sources and development of pedagogical content knowledge. In: J. Gess-Newsome, \& N. G. Lederman (Eds.), Examining pedagogical content knowledge: the construct and its implications for science education, pp. 95-132. Dordrecht: Kluwer Academics. 1999.

Marcelo, C. La investigación sobre el conocimiento de los profesores y el proceso de aprender a enseñar. En: Perafán G.A. \& Adúriz-Bravo, A. Pensamiento y conocimiento de los profesores: debates y perspectivas internacionales. 2a Ed., pp. 47-61. Bogotá: Editorial Nomos. 2005.

Mertens, D. M. Research and evaluation in education and psychology: integrating diversity with quantitative, qualitative, and mixed methods. London: Sage Publications. 2015.

Mortimer, E. F., \& Quadros, A. L. Multimodalidade no Ensino Superior. Ijuí: Ed. Unijuí. 2018.

Mortimer, E. F., \& Scott, P. Atividade discursiva nas salas de aula de ciências: uma ferramenta sociocultural para analisar e planejar o ensino. Investigações em Ensino de Ciências, 7(3), 1-24. 2002.

Park, S., \& Oliver, S. Revisiting the conceptualization of pedagogical content knowledge (PCK): PCK as a conceptual tool to understand teachers as professionals. Research in Science Education, 38, 261-284. 2008. <https://doi.org/10.1007/s11165007-9049-6>.

Park, S., Jang, J.-Y., Chen, Y. C., \& Jung, J. Is pedagogical content knowledge (PCK) necessary for reformed science teaching? Evidence from an empirical study. Research in Science Education, 41, 245-260. 10.1007/s11165-009-9163-8. 2011.

Rollnick, M., Bennett, J., Rhemtula, M., Dharsey, N., \& Ndlovu, T. The place of subject matter knowledge in pedagogical content knowledge: A case study of South African teachers teaching amount of substance and chemical equilibrium. International Journal of Science Education, 30(10), 1365-1387. 2008. <https://doi.org/10.1080/09500690802187025>.

Shulman, L. S. Knowledge and teaching: foundations of a new reform. Harvard $\begin{array}{llll}\text { Educational } & \text { Review, } & 57(1), & 1-23 .\end{array}$ <https://doi.org/10.17763/haer.57.1.j463w79r56455411>.

Van Driel, J. H., \& Berry, A. Teacher professional development focusing on pedagogical content knowledge. Educational Researcher, 41(1), 26-28. 2012. <https://doi.org/10.3102/0013189X11431010>.

Van Driel, J. H., De Jong, O., \& Verloop, N.The development of preservice chemistry teachers' pedagogical content knowledge. Science Education, 86(4), 572-590. 2002. <https://doi.org/10.1002/sce.10010>. 


\section{Carmen Fernandez}

Livre docente em Ensino de Química. Professora Associada do Departamento de Química Fundamental do Instituto de Química da Universidade de São Paulo (QFL IQUSP). Coordenadora do grupo PEQuim (Pesquisa em Ensino de Química) IQ-USP Universidade de São Paulo, Instituto de Química, São Paulo, SP - Brasil.

E-mail:carmen@iq.usp.br

\section{Aroldo Nascimento Silva}

Doutor em Educação. Programa de Pós Graduação Interunidades em Ensino de Ciências. Universidade de São Paulo, Instituto de Química, São Paulo, SP - Brasil. E-mail: arosilva32@gmail.com

Contato da autora:

Instituto de Química - Universidade de São Paulo Av. Prof. Lineu Prestes, 748, sala 773, Cidade Universitária São Paulo, SP - Brasil

CEP 05508-000

\section{Editor Responsável}

Luciana Massi

Centro de Ensino de Ciências e Matemática de Minas Gerais - CECIMIG Faculdade de Educação - Universidade Federal de Minas Gerais revistaepec@gmail.com 